\title{
OCCUPATIONAL HEALTH ASSESSMENT OF RICE MILLS' WORKERS IN NORTH-EAST, INDIA
}

\author{
Mrinmoy Biswas ${ }^{1 *}$, P. K. Pranav², Sonu Kumar ${ }^{3}$, Ritesh Ranjan ${ }^{3}$ \\ ${ }^{1}$ Department of Agricultural Engineering, Birsa Agricultural University (BAU), Kanke- 834006, Jharkhand, India. \\ ${ }^{2}$ Dr. Rajendra Prasad Central Agriculture University, Pusa, Samastipur - 848 125, Bihar. \\ ${ }^{3}$ Department of Agricultural Engineering, NERIST, Nirjuli - 791 109, Arunachal Pradesh. \\ Received - April 18, 2019; Revision - June 21, 2019; Accepted - July 20, 2019 \\ Available Online - August 05, 2019
}

DOI: http://dx.doi.org/10.18006/2019.7(4).349.357

\section{KEYWORDS}

Rice mill

Ovako Working Posture

Analysis System (OWAS)

Posture

Discomfort

Health status

\footnotetext{
* Corresponding author

E-mail: mrinmoyiitkgp@gmail.com (Mrinmoy Biswas)
}

Peer review under responsibility of Journal of Experimental Biology and Agricultural Sciences.

Production and Hosting by Horizon Publisher India [HPI] (http://www.horizonpublisherindia.in/).

All rights reserved.

\begin{abstract}
Assam has more than four thousand old rice mills where large numbers of workers are employed. They are involved in various kind of works namely loading/unloading, spreading, bag opening at feeding, filling, sewing, separate broken rice from husk and bag repairing, respectively. The present study was undertaken to evaluate the rice mill workers health status. A total of 145 rice mill workers were selected from 18 rice mill of Assam. A modified Nordic questionnaire and posture analysis using OWAS method were used. Polar heart rate monitor was used to measure the workers heart rate. The PEFR test was carried out by a Portable micro-quark spirometer for the selected subjects. The analysis of OWAS method indicated that most of the working posture of the workers needed immediate actions to improve working conditions as well as the technical equipment. Rice mill workers are suffered from discomfort feeling in different body parts and maximum discomfort reported in lower back $(68.9 \%)$. It was observed that loading/unloading type of workers is suffered maximum discomfort manifestation compare to the other types of rice mill workers. Average working heart rate (138.1 beats/min) which was observed in loading/unloading workers which is indicated heavy work load and extremely high category drudgery index. Further, it was observed that the mean value of PEFR is $22.9 \%$ and it was lower for second level of experience compared to first level of experience. From the analysis it was concluded that rice mill workers health are highly affected by improper bending posture and work load in dusty condition.
\end{abstract}

All the articles published by Journal of Experimental Biology and Agricultural Sciences are licensed under a Creative Commons Attribution-NonCommercial 4.0 International License Based on a work at www.jebas.org.

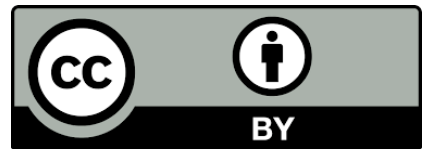




\section{Introduction}

Rice is one of the most important cereal crop in the world. India is the world second largest rice producer (Khatkar et al., 2016). It is the main staple food for most of the Indian population. It is the largest consumed calorific source among the food grains. India being a land of agriculture has formed scaffolding for many agrobased industries. The post-harvest processing of paddy (de-husking) is the oldest and largest agro processing industry of the country. Assam state consists of 4645 rice mills which include 1363 modern and remaining traditional mills (Mauskar, 2008). Average number of labour per day employed in each mill of Assam varies from 20 to 40 through a lesser number is also found in very small establishments. Rice mill workers are suffered by airborne dust which is effect on pulmonary functions. Pranav \& Biswas, (2016) and Biswas \& Pranav, (2017) reported that, total dust concentration at feeding-cum-sieving section varied $73-80 \mathrm{mg} / \mathrm{m}^{3}$ and respirable dust concentration was varied $9-11 \mathrm{mg} / \mathrm{m}^{3}$ however, recommended value of respirable dust concentration is $5 \mathrm{mg} / \mathrm{m}^{3}$ (Swedish National Board of Occupational safety and Health, 1991). Workers those who are potentially exposed to organic dust have high prevalence of respiratory disease (Oxman et al., 1993). Several reports (Taskar \& Coultas, 2006; Schenker et al., 2009; Nordgren\& Bailey, 2016; Said et al., 2017) have suggested that unprotected dust exposures in agricultural settings may lead to pulmonary fibrosis. Grain dust has also long history of association with various diseases, and ithas adverse effects on various organs such as eyes, nose, skin, lung and the airways (Hurst \& Dosman, 1990). Industrial dust inhalation over a long period leads to proliferative and fibrotic changes in the lungs (Dhillon et al., 2012). Agricultural workers are also experienced with most common type of work-related musculoskeletal disorders (MSDs) injuries due to repetitive motions of heavy lifting and performing tasks (Jadab, 2012). Musculoskeletal disorders are a common health problem and major cause of disability throughout the world. According to a survey of self-reported work-related illness (Jones et al., 1998); approximately forty three thousand agricultural workers from Britain ascribe musculoskeletal symptoms to their work, including $62.7 \%$ with back pain, $23.2 \%$ with upper limb or neck complaints, and $25.5 \%$ with work related musculoskeletal disorders (MSDs) of the lower limb. Paul et al. (2019) also studied in agricultural workers in West Bengal, India and reported that musculoskeletal disorders were found to be maximum $32.38 \%$ in the lower back followed by knee $(30.95 \%)$, neck $(12.86 \%)$, shoulder $(12.38 \%)$ and upper back $(12.38 \%)$. The economic loss due to such disorders affects not only the individual but also the organization and the society as a whole (Kemmlert, 1994). Blatter et al. (1999) conducted a study in different industrial settings on 10,813 volunteers and reported that neck and upper limb discomfort symptoms of tailors (47\%), building construction workers $(43 \%)$, loading/unloading workers $(42 \%)$, secretaries and typist (38\%) and commercial occupations (21\%).
Rice mill workers are involved invarious activities such as loading/unloading, spreading, bag opening at feeding, filling, sewing, separate broken rice from husk and bag repairing, respectively. In Assamrice mill workers are worked more than 8 to 10 hours daily. In the most of rice mill of Assam these activities are mostly carried out manually by the workers. Often, the workers have to adopt awkward postures to carry sacs of paddy and rice for loading into the vehicles. Workers are suffered musculoskeletal disorder problem due to working in awkward posture with heavy load which adversely affects on physiological strain, back pain. Due to this posture related discomfort which leads to the labour shortage of manpower. It is well known fact that agriculture and its allied sectors in India are a forced profession and not a preferred profession which results in migration of labour from rural area to urban area.The main reason for which the agriculture became an ignorant profession with drudgeries and hazardous operation which reduces of their health status. Rice mill workers are suffered musculoskeletal disorder problem due to working in awkward posture with heavy load and repetitive work at different places of work in the workplace of rice mills. This morbidity pattern may disturb their regular work, which may affect the gross production of most needed commodity (rice) of the state.The present study was undertaken to evaluate the rice mill workers health status and nature of work load with respect to their posture, musculoskeletal pain, workload, energy expenditure and peak expiratory flow.

\section{Materials and Methods}

\subsection{Study area}

The study area was the old rice mills of two districts of Assam namely North-Lakhimpur and Dhemaji. There are nearly 120 rice mill units in the area of study, employing approximately 500 workers. Considering the logistics supports as well as participation consent of mill owner, eighteen rice mills were selected for the study. Thepresent study was carried out during December 2015-August 2017.

\subsection{Selection of subjects}

The study design involved a group of 145 rice mill workers from seven different types of activities in rice mill namely Type A (loading/unloading), Type B (spreading), Type C (bag opening at feeding section), Type D (filling paddy/rice), Type $\mathrm{E}$ (sewing rice bag), Type $\mathrm{F}$ (separate broken rice from husk) and Type $G$ (damage bag repairing). These activities are described in Table 1. The selected workers were in the age range of 18-60 years. The demographic details of the subjects along with history of smoking were recorded. The study was approved by NERIST ethics committee and written consent was taken from the subjects before the study. 
Table 1 Various activities carried out by workers in rice mill

\begin{tabular}{|cccl|}
\hline S. $\mathbf{N}$ & Type & Activity & \multicolumn{1}{c|}{ Description } \\
\hline 1 & Type $\mathrm{A}$ & Loading/unloading & Loading/unloading paddy or rice bag from vehicles \\
\hline 2 & Type $\mathrm{B}$ & Spreading/gathering & Spreading or gathering paddy on floor by the wooden spreader \\
\hline 3 & Type $\mathrm{C}$ & Bag opening & Paddy bag opening at feeding section \\
\hline 4 & Type $\mathrm{D}$ & Filling rice/paddy & Rice/paddy filling at packaging /storage section by the iron (spade) belcha. \\
\hline 5 & Type $\mathrm{E}$ & Sewing rice bag & Sewing rice bag after filling by power operated sewing machine. \\
\hline 6 & Type $\mathrm{F}$ & Separate broken rice & Broken rice separate from the husk by bamboo madeseparator. \\
\hline 7 & Type $\mathrm{G}$ & Bag repairing & Damage bag repairing by the needle. \\
\hline
\end{tabular}

\subsection{Questionnaire study}

A musculoskeletal disorder questionnaire based on Dickinson et al. (1992) was developed and applied for the selected subjects. The questionnaire consisted of a series of objective questions with multiple type choice answers identifying the subjects'personal viewpoints, pattern of work duration of work and discomfort levels in different parts of the body. Each subjects was approached by researcher and was explained the aim of the study.

\subsection{Analysis of working posture}

The posture which is of longest duration was identified as awkward posture for each operation. These postures were analyzed through Ovako Working posture Analysis System (OWAS) to find out the OWAS code and risk class (Karhu et al., 1977). The OWAS code was depended on four different factors such as back position, forearm position, legs work and external load. Further, duration, bending angle and interval of awkward posture was also noted from the recorded video clippings for all the operations. The postural angle was measured using Kinovea software.

\subsection{Assessment of Physiological Stress}

Physiological stress assessment was carried out by polar heart rate monitor of the rice mill workers. The selected subject was called for the experiment and heart rate monitor was appropriately fixed to him and was made ready for the experiment. He allowed to relax for 15 minutes silently. After resting the subject was asked to perform his work for 30 minutes. The heart rate obtained for all the subjects were averaged to get the mean values of the workers of that section. During the measurement of heart rate ambient temperature range was $18-27^{\circ} \mathrm{C}$. Maximum heart rate (MHR) was calculated of a particular subjects by deducting age in 220 (AHA, 1972). Heart rate reverse (HRR) was determined as the difference between maximum heart rate and resting heart rate. Net cardiac cost (NCC) and Relative cardiac cost (RCC) were calculated as indicator of the cardiac strain (Dey \& Sharma, 2014).

\subsection{Measurement of the Peak Expiratory Flow Rate (PEFR)}

Measurement of the peak expiratory flow rate (PEFR) was conducted using portable micro-quark spirometer equipment, with Omnia 1.2 software (COSMED, Italy). The apparatus was calibrated daily and operated within the ambient temperature range of $18-27^{0} \mathrm{C}$. The test was performed with the subject in sitting position using a nose clip. The test was repeated three times after adequate rest, and the best of three were taken for further analysis.

\subsection{Data analysis}

The collected data were analyzed and expressed as mean \pm SD and percentage. Occupational related discomfort problems of rice mill workers with different age groups are presented in graphically. Statistical analysis was carried out using IBM SPSS (version 22), and the summary of statistics are presented. Independent sample $\mathrm{t}$ test was performed between the two different experience groups of workers to find out whether there was any significance difference or not by $p$ value.

\section{Results and Discussion}

\subsection{Physical Characteristics of Subjects}

Physical characteristics of selected subjects are given in Table 2. Mean age of subjects were observed 39.3 years and about $30 \%$

Table 2 Physical characteristics of rice mill workers and control volunteers

\begin{tabular}{|lcc|}
\hline & \multicolumn{2}{c|}{ Rice mill workers } \\
Parameters & Mean & SD \\
\hline Age (years) & 39.3 & 11.5 \\
\hline Body height $(\mathrm{cm})$ & 164.6 & 5.1 \\
\hline Body weight $(\mathrm{kg})$ & 57.8 & 11.4 \\
\hline BMI (kg/m $\left.{ }^{2}\right)$ & 21.7 & 3.4 \\
\hline BSA (m $\left.{ }^{2}\right)$ & 1.6 & 0.2 \\
\hline Working experience (years) & 7.1 & 6.1 \\
\hline
\end{tabular}


Table 3 Frequency of postural change of related respondents

\begin{tabular}{|c|c|c|c|c|c|c|c|c|}
\hline $\begin{array}{l}\text { Nature of } \\
\text { work }\end{array}$ & Figure & posture & $\begin{array}{l}\text { OWAS } \\
\text { code }\end{array}$ & $\begin{array}{l}\text { Class } \\
\text { risk }\end{array}$ & Remarks & $\begin{array}{l}\text { AAPD } \\
(\mathrm{sec})\end{array}$ & $\begin{array}{l}\text { AFAP } \\
(\text { no/h) }\end{array}$ & $\begin{array}{l}\text { MFB } \\
\text { (deg.) }\end{array}$ \\
\hline Type-A & & $\begin{array}{l}\text { Back bent forward and both } \\
\text { hand above shoulder level, } \\
\text { one knee bent (walking or } \\
\text { moving), weight greater than } \\
20 \mathrm{~kg} \text {. }\end{array}$ & 4353 & 4 & $\begin{array}{l}\text { Corrective action } \\
\text { immediately }\end{array}$ & 18 & 73 & 52 \\
\hline Type-B & & $\begin{array}{l}\text { Back bent slightly forward, } \\
\text { both arms below shoulder } \\
\text { level, both knee straight, } \\
\text { weight less than } 10 \mathrm{~kg} \text {. }\end{array}$ & 2121 & 2 & $\begin{array}{l}\text { Corrective action } \\
\text { near future }\end{array}$ & 215 & 13 & 24 \\
\hline Type-C & & $\begin{array}{l}\text { Back bent forward and both } \\
\text { hand below shoulder level, } \\
\text { both knee bent, weight greater } \\
\text { than } 20 \mathrm{~kg} \text {. }\end{array}$ & 4143 & 4 & $\begin{array}{l}\text { Corrective action } \\
\text { immediately }\end{array}$ & 11 & 29 & 54 \\
\hline Type-D & & $\begin{array}{c}\text { Back bent forward and both } \\
\text { hand below shoulder level, } \\
\text { one knee bent, weight less } \\
\text { than } 10 \mathrm{~kg} \text {. }\end{array}$ & 4131 & 4 & $\begin{array}{l}\text { Corrective action } \\
\text { immediately }\end{array}$ & 45 & 36 & 48 \\
\hline Type-E & & $\begin{array}{l}\text { Back bent forward and both } \\
\text { hand below shoulder level, } \\
\text { one knee bent, weight less } \\
\text { than } 10 \mathrm{~kg} \text {. }\end{array}$ & 4121 & 4 & $\begin{array}{l}\text { Corrective action } \\
\text { immediately }\end{array}$ & 180 & 18 & 53 \\
\hline Type-F & & $\begin{array}{l}\text { Back straight and both hand } \\
\text { below shoulder level, } \\
\text { kneeling on both knee, weight } \\
\text { less than } 10 \mathrm{~kg} \text {. }\end{array}$ & 1161 & 2 & $\begin{array}{l}\text { Corrective action } \\
\text { near future }\end{array}$ & 250 & 15 & 12 \\
\hline Type -G & & $\begin{array}{l}\text { Back leaning forward and } \\
\text { both hand below shoulder } \\
\text { level, kneeling on both knee, } \\
\text { weight less than } 10 \mathrm{~kg} \text {. }\end{array}$ & 1261 & 3 & $\begin{array}{l}\text { Corrective action } \\
\text { as soon as } \\
\text { possible }\end{array}$ & 152 & 13 & 23 \\
\hline
\end{tabular}

AAPD- Average awkward posture duration (sec), AFAP- Average frequency of awkward posture (no/h), MFB- Maximum forward bending (deg.).

workers are selected in the 20-30 years age group. Measured body height and body weight of workers were observed $164.6 \mathrm{~cm}$ and $57.8 \mathrm{~kg}$, respectively. The BMI of rice mill workers was found in the normal range $\left(18.5-24.9 \mathrm{~kg} / \mathrm{m}^{2}\right)$ which indicates the right selection of the subjects (WHO, 1995). Average working experiences of rice mill workers were found 7.1 years.

\subsection{Posture analysis with frequency of postural change}

The operation wise posture details, awkward posture duration and frequency are given in Table 3. The table also contains the OWAS code and class risk calculated as per the postural details and load carrying. Out of seven types of operations four types of working postures namely Type A, C, D and E were found under high risk 


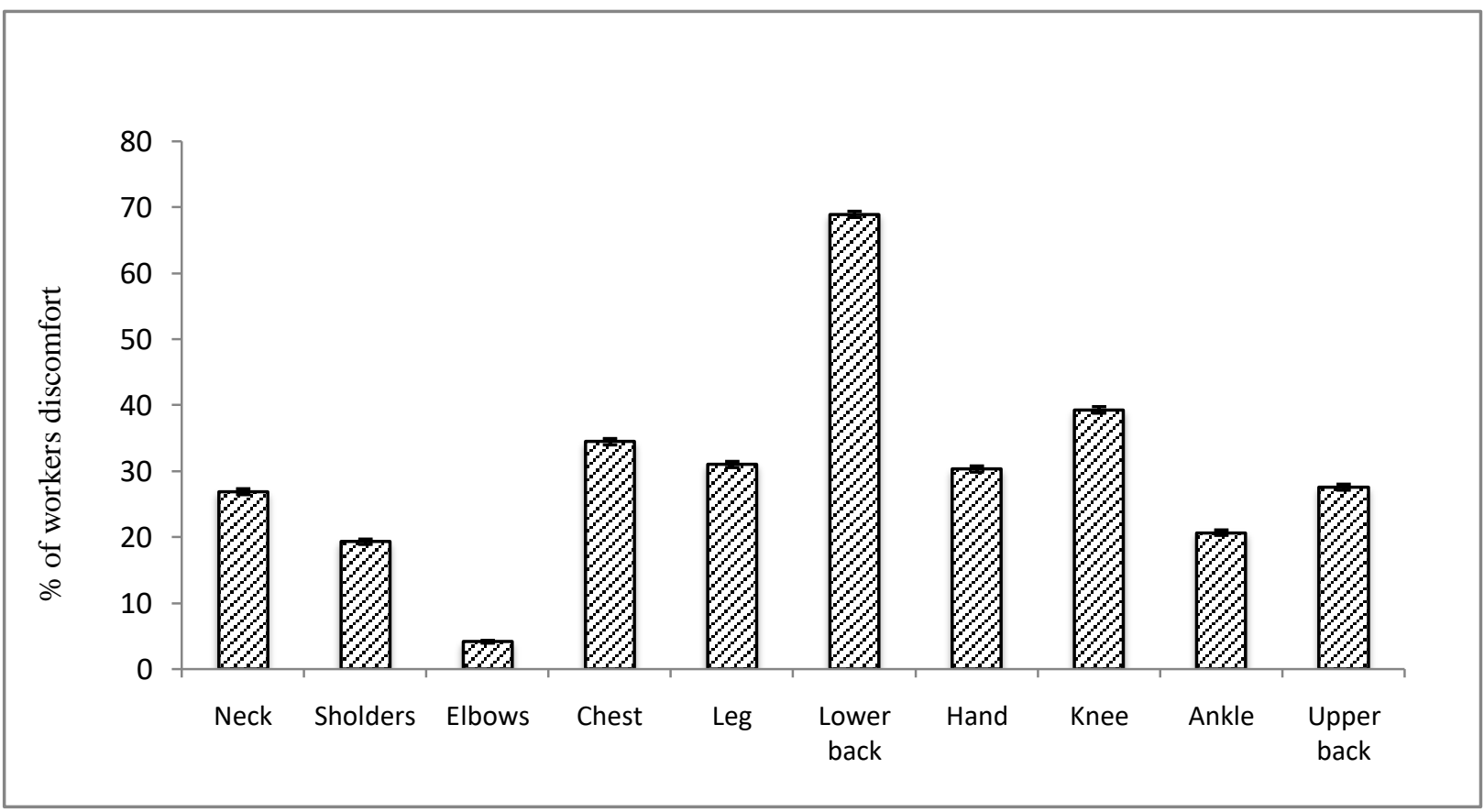

Figure 1 Discomfort feeling (pain) at different body parts among rice mill workers

(4). The high risk means immediate action is required to improve working conditions. Operation type $G$ was found medium category risk (3) which to be taken corrective action as soon as possible and working type $\mathrm{B}$, and $\mathrm{F}$ were found lower action category risk (2) which to be required corrective measure in near future. Several studies (Gangopadhyay et al., 2005; Das \& Gangopadhyay, 2011; Das et al., 2013) reported that working in awkward posture may lead to back pain in agricultural sector.

The awkward posture duration (sec), frequency of awkward posture (no/h) and maximum forward bending (deg.) were measured from the video clipping taken for different workers during actual working condition in the rice mill. The results observed that average duration of awkward posture varied 18-250 sec which is adversely affected in musculoskeletal disorder and average frequency of awkward posture per hour lied 13-73. It was revealed that rice mill workers have spent most of the time in a high hazardous position with a high degree of static load. Lower back pain is also associated with handling of heavy materials linking awkward posture (Awang et al., 2017). It was observed that the maximum forward bending was $54^{\circ}$ in Type $\mathrm{C}$ work followed by Type E, Type A, Type D, Type B, Type G and Type $\mathrm{F}$ which lies in the range of awkward posture. Forward bending posture with heavy load affect the moment of force applied in the lumber region (McGill \& Norman, 1985). Awkward posture working is mainly associated musculoskeletal disorder (Kivi \& Mattila, 1991; Gangopadhyay et al., 2010; Das et al., 2013). Awkward postures such as bending of lumber region and twisting of trunk adopted frequently causes the discomfort problem (Pradhan et al., 2007).

\subsection{Discomfort feeling or pain of rice mill workers}

The selected subjects were given multiple responses regarding discomfort in various parts of the body. The percentage of discomforts is presented in graphically (Figure 1). In rice mill workers, maximum reported discomfort in lower back (68.9\%) followed by knee $(39.6 \%)$, chest $(34.3 \%)$, leg $(31 \%)$, hand (30.3\%), upper back $(27.6 \%)$, neck $(26.9 \%)$, ankles $(20.7 \%)$, shoulder $(19.3 \%)$ and elbow $(4.1 \%)$. It was also found that the average discomfort symptoms of body parts of rice mill workers were 3 out of 10 different body parts.Several studies (Pradhan et al., 2007; Puttewar \& Jaiswas, 2014) reported that rice mill workers are affected mostly in low back pain.

\subsection{Occupational related present discomfort problems of workers with different age groups}

Present discomfort of rice mill workers were also analyzed based on work experience, age wise and type of operation as given in 


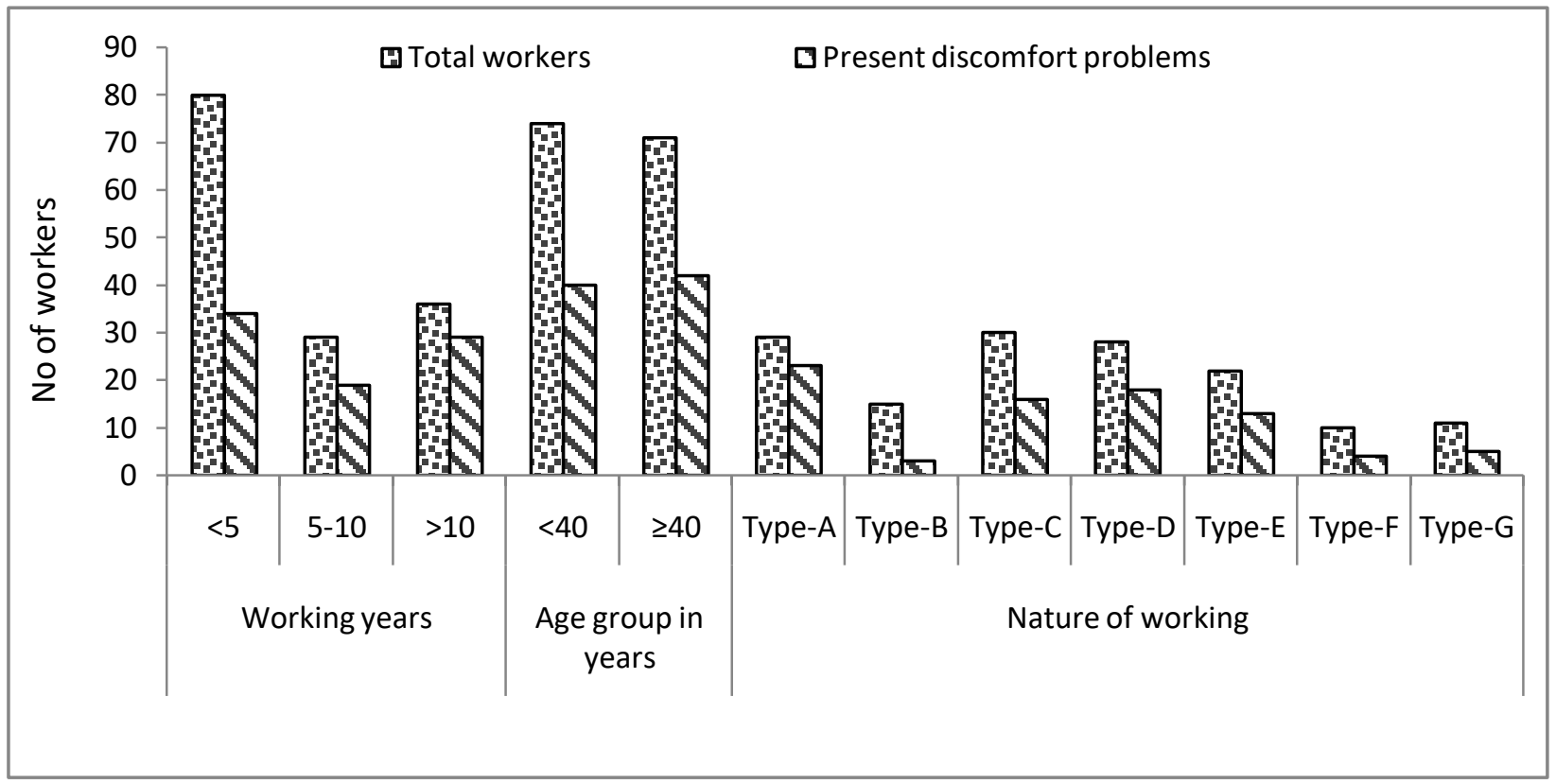

Figure 2 Present occupational related discomfort problems with different age groups

Figure 2. As per working experience, rice mill workers are divided in three categories such as less than 5 years, 5-10 years and greater than 10years. Out of total 145 rice mill workers, 82 $(56.6 \%)$ workers have present discomfort or pain with different body parts. It was found that less than 5 years' experience workers have less percentage of discomfort or pain compare to the other two groups of experience. In case age wise distribution, two subgroups were divided such as $<40$ years and $\geq 40$ years. Present discomfort or pain of both groups was found nearly similar results. So discomfort or pain mainly depends upon year of experience. Among the present discomfort manifestation, about $42.7 \%$ workers are working in rice mill greater than 10 years followed by $34.7 \%$ workers in 5-10 years and $22.5 \%$ workers in less than 5 years, respectively. Darbastwar et al. (2016) reported that $45.7 \%$ rice mill workers are significantly associated in musculoskeletal disorder (MSD) with year of experience.

Total seven types (Type A-G) of workers are selected to find out the present discomfort manifestation. It was observed that Type A workers are suffering maximum discomfort manifestation (79.3\%) among the other types of rice mill workers due to they have worked more time $(18 \mathrm{sec})$ continuously with forward bending posture to carry 40-60 kg load. Type A workers are suffering highest $21.9 \%$ of total present discomfort manifestation followed by Type D (17.8\%), Type E (16.3\%), Type C (14.8\%), Type G (12.6\%), Type F $(11.1 \%)$ and Type B (5.5\%), respectively.

\subsection{Physiological parameter}

Physiological parameters such as heart rate, heart rate reverse (HRR) and relative cardiac cost (RCC) is given in Table 4. From the measurement of heart rate, it was reported that mean resting heart rate was varied $77-80$ beats/min which is indicated in the normal range. Maximum of average working heart rate (138.1 beats/min) was observed in Type A which is indicated extremely high category drudgery index (Mirunalini et al., 2015). Permissible limit of heart rate is $120-130$ beats/min for an 8 hour working day suggested by Astrand (1960). Second highest of mean working heart rate (121.7 beats/min) was observed in Type D operation (very high category drudgery index as suggested by Mirunalini et al., 2015) followed by Type B, Type E, Type C, Type F and Type G. Similar mean working heart rate was observed for Type B, C, F and E work which is indicated high category drudgery index (Mirunalini et al., 2015). These four types of works were found nonsignificant. Lowest of mean working heart rate (93.8 beats/min) was observed in Type G which is moderate category drudgery index (Mirunalini et al., 2015). According to classification for Indian industrial workers (Sen \& Nag, 1975) workloads were classified on the basis of heart rate such as moderate (100-125 beats/min), heavy (125-150 beats/min), very heavy (150-175 beats/min) and extremely heavy (>175 beats/min). As per reported Sen \& Nag (1975), Type A and Type B-F operations were indicated heavy and moderate workloads, respectively. Maximum net cardiac cost (NCC) and relative cardiac 
Table 4 Physiological parameter of rice mil workers

\begin{tabular}{|c|c|c|c|c|c|c|c|}
\hline Nature of works & $\begin{array}{c}\text { RHR (b/m) } \\
\text { a }\end{array}$ & $\begin{array}{c}\text { AWHR (b/m) } \\
\text { b }\end{array}$ & $\begin{array}{c}\text { PWHR (b/m) } \\
\text { c }\end{array}$ & $\begin{array}{c}\text { Max. } \operatorname{HR}(\mathrm{b} / \mathrm{m}) \\
\mathrm{d}\end{array}$ & $\begin{array}{c}\operatorname{HRR}(\mathrm{b} / \mathrm{m}) \\
(\mathrm{d}-\mathrm{a})\end{array}$ & $\begin{array}{c}\mathrm{NCC}(\mathrm{b} / \mathrm{m}) \\
(\mathrm{b}-\mathrm{a})\end{array}$ & $\begin{array}{c}\operatorname{RCC}(\%) \\
(d-a) / \\
(b-a) * 100\end{array}$ \\
\hline Type-A (N=29) & $79.1 \pm 4.2$ & $138.1 \pm 10.7$ & $151.0 \pm 12.6$ & $182.2 \pm 12.9$ & $103.1 \pm 14.2$ & $59.0 \pm 11.0$ & $58.2 \pm 13.0$ \\
\hline Type-B $(\mathrm{N}=15)$ & $77.8 \pm 7.1$ & $112.3 \pm 7.2$ & $125.6 \pm 8.2$ & $184.7 \pm 9.0$ & $106.9 \pm 9.7$ & $34.5 \pm 9.0$ & $32.8 \pm 10.0$ \\
\hline Type-C $(\mathrm{N}=30)$ & $77.5 \pm 6.3$ & $109.2 \pm 3.7$ & $123.5 \pm 5.7$ & $176.0 \pm 12.0$ & $98.5 \pm 11.5$ & $31.7 \pm 6.4$ & $32.4 \pm 6.6$ \\
\hline Type-D (N=28) & $80.1 \pm 10.0$ & $121.7 \pm 9.1$ & $133.8 \pm 9.7$ & $183.0 \pm 9.8$ & $102.9 \pm 13.5$ & $41.5 \pm 11.2$ & $40.3 \pm 9.2$ \\
\hline Type-E (N=22) & $77.7 \pm 4.3$ & $110.4 \pm 6.4$ & $122.0 \pm 5.9$ & $181.4 \pm 11.3$ & $103.7 \pm 11.2$ & $32.7 \pm 7.5$ & $31.8 \pm 7.8$ \\
\hline Type-F $(\mathrm{N}=10)$ & $79.7 \pm 2.8$ & $109.1 \pm 12.5$ & $122.7 \pm 12.7$ & $177.7 \pm 9.0$ & $98.0 \pm 8.4$ & $29.4 \pm 13.7$ & $30.6 \pm 14.6$ \\
\hline Type-G $(\mathrm{N}=11)$ & $77.2 \pm 7.5$ & $93.8 \pm 4.3$ & $107.6 \pm 5.5$ & $179.5 \pm 10.1$ & $102.3 \pm 14.1$ & $16.6 \pm 7.3$ & $16.0 \pm 6.5$ \\
\hline
\end{tabular}

RHR-Resting heart rate, AWHR-Average working heart rate, PWHR-Peak working heart rate, MHR-Maximum heart rate, b/m-beats/minute; value give in table is Mean $\pm \mathrm{SD} ; \mathrm{N}-$ Number of workers

Table 5 Peak expiratory flow rate (PEFR) among rice mill workers and control volunteers

\begin{tabular}{|llccccccccc|}
\hline \multirow{2}{*}{ Parameters } & \multicolumn{2}{l}{ Experience $\leq 10$ years } & \multicolumn{2}{l}{ Experience $>10$ years } & F-value & t-value & MD & SED & $95 \%$ CI & p-value \\
& Mean $(\mathrm{N})$ & SD & Mean $(\mathrm{N}) \mid$ & SD & & & & & & \\
\hline PEFR $(1 / \mathrm{s})$ & $4.8(109)$ & 1.8 & $3.7(36)$ & 1.7 & 0.02 & 2.9 & 0.98 & 0.34 & $0.3,1.64$ & 0.004 \\
\hline
\end{tabular}

cost (RCC) was observed in Type A operation which was highest cardiac strain among the other types of operation in rice mill. Relative cardiac cost (RCC) of different type of rice mill workers were varied $16-58.2 \%$ and heart rate reverse (HRR) maximum (106.9 beats/min) was observed in Type B.

\subsection{Lung function test of rice mill workers}

The comparison of peak expiratory flow rate (PEFR), rice mils workers are divided two groups as per experience wise such as $\leq 10$ years and $>10$ years' experience, respectively which are given in Table 5. Also it was observed that the mean value of PEFR is $22.9 \%$ lower for s econd level of experience compared to first level of experience. From the analysis, it was found statically significant $(p<0.05)$ between two level of experience groups. Irrespective of experience, PEFR of rice mill workers was observed $4.5 \pm 1.8 \mathrm{l} / \mathrm{s}$. As per previous study (Biswas, 2017) in this region, control group of subjects (not exposed any kind of dust) PEFR was found $7.15 \mathrm{l} / \mathrm{s}$ which is $37.06 \%$ higher than rice mill workers. For rice mill, the PEF was reported as 5.08 and 4.29 L/s by Ghosh et al. (2014) and Dhillon \& Kaur (2011) and FEF $25-75 \%$ was reported as $2.82 \mathrm{~L} / \mathrm{s}$ by Dhillon \& Kaur (2011). Decrease in PEFR is probably due to hypertrophy of mucosal cells by grain dust resulting in the increased formation of mucosal plugs which cause obstruction to the respired air (Yach et al., 1985; Taytard et al., 1988).

\section{Conclusions}

Most of the postures adopted by rice mill workers are highly affected as discovered by OWAS method. Rice mill workers are suffered discomfort feeling in different body parts and maximum discomfort reported in lower back. It was observed that loading/unloading type of workers is suffering maximum discomfort manifestation compare to the other types of rice mill workers. Present discomfort manifestation was reported approximately half of the workers are working in rice mill who have worked greater than ten years. Further, it was observed that the mean value of PEFR is $22.9 \%$ lower for second level of experience compared to first level of experience. More experienced workers were significantly lower $(\mathrm{p}<0.05)$ PEFR compared to the lesser experienced group.

\section{Acknowledgment}

Authors acknowledge the ICAR, New Delhi for providing financial support to carry out this research. Also authors are thankful to rice mill owner and workers who supported for conducting the experiment.

\section{References}

American Heart Association, Committee of exercise (1972) Exercise testing and training of apparently healthy individual: a handbook of physician. New York: American Heart Association. 
Astrand I (1960) Aerobic work capacity in men and women with special reference to age. Acta Physiologica Scandinavica 49: 169.

Awang LK, Jeffree MS, Rampal KG (2017) Low Back Pain and Its Association with Whole Body Vibration and Manual Material Handling Among Commercial Drivers in Sabah.International Journal of Occupational Safety and Ergonomics 5: 1-18.

Biswas M (2017) Effect of dust on workers' health and its minimization in rice mills of Assam. Ph.D Thesis submitted to NERIST, Nirjuli, Arunachal Pradesh.

Biswas M, Pranav PK (2017) Evaluation of personal dust exposure of the rice mill workers in Assam. International Journal of Advanced in Management, Technology and Engineering Sciences 7: 66-75.

Blatter BM, Bongers PM, Writte HD (1999) Work related neck and upper limb symptoms: High risk occupations and risk factors in the Belgian working population, TNO-repoñ 4070t 17V9900409.

Darbastwar MA, Kumar B, Ravinder A (2016) A study of prevalence of musculoskeletal disorder among the rice mill workers in Karimnagar. Journal of Evolution of Medical and Dental Sciences 5: 1106-1110.

Das B, Gangopadhyay S (2011) An ergonomics evaluation of posture related discomfort and occupational health problem among rice farmers. Occupational Ergonomics 10: 25-38.

Das B, Ghosh T, Gangopadhyay S (2013) Prevalence of musculoskeletal disorder and occupational heal problem among groundnut farmers of West Bengal. Journal of Human Ergology 42: 1-12.

Dey NC, Sharma GD (2014) Environmental Impact on Physiological Responses of Underground Coal Miners in the Eastern Part of India. Journal of Human Ergology 43: 69-77.

Dhillon SK, Bassi R, Thamman RG (2012) Effect of Flour Dust on Lung Volumes and Capacities in Flour Mill Workers. National Journal of Integrated Research in Medicine 3 : 95-104.

Dhillon SK, Kaur H (2011) Study of effect of flour dust and rice husk dust on pulmonary functions. Indian Journal of Fundamental and Applied Life Sciences 1: 100-106.

Dickinson CE, Campion K, Foster AF, Newman SJ, O'Rourke AMT, Thomas PG (1992) Questionnaire development: an examination of the Nordic Musculoskeletal Questionnaire. Applied Ergonomics 23: 197-201.

Gangopadhyay S, Das B, Das T, Ghoshal G (2005) An ergonomic study on posture related discomfort feeling among the pre- adolescent agricultural workers of West Bengal, India. International Journal of Occupational Safety and Ergonomics11: 315-322.

Gangopadhyay S, Ghosh T, Das T, Ghoshal G, Das B (2010) Effect of working posture on occurance of musculoskeletal disorder among the sand core making workers of West Bengal. Central European Journal of Public Health 18: 38-42.

Ghosh T, Gangopadhya S, Das B (2014) Prevalence of respiratory symptoms and disorders among rice mill workers in India. Environmental Health and Preventive Medicine19: 226-233.

Hurst TS, Dosman JA (1990) Characterization of health effects of grain dust exposures.American Journal of Industrial Medicine 17: 27-32.

Jadab KB (2012) Occupational health hazards and safety management for industrial workers. Odisha Review 64-69.

Jones JR, Hodgson JT, Clegg TA (1998) Self-reported work related illness and workplace injuries in 2008/09, Results from a household survey.

Karhu O, Kansi P, Kuorinka I (1977) Correcting work postures in industry: a practical method for analysis. Applied Ergonomics 8: 199-201.

Kemmlert K (1994) Labor inspectorate investigation for the prevention of occupational musculoskeletal injuries, national Institute of Occupational Health, Solna, Sweden.

Khatkar B, Chaudhary N, Dangi P (2016) Production and Consumption of Grains in India. Encyclopedia of Food Grains 1: 367-373.

Kivi P, Mattila M (1991) Analysis and improvement of work postures in the building industry: application of the computerized OWAS method. Applied Ergonomics 22: 43-48.

Mauskar JM (2008) Comprehensive Industry Document on Pulse, Wheat, Rice Mills. Central Pollution Control Board.Ministry of Environment \& Forests, Govt. of India. Available on http://cpcb.nic.in/openpdffile.php?id=UmVwb3J0RmlsZXMvTm V3SXRlbV8xMzJfY29pbmQtcHVsc2V3aGVhdHJpY2VtaWxscy $5 \mathrm{wZGY}=$ access on $29^{\text {th }}$ April, 2019.

McGill SM, Norman RW (1985) Dynamically and statistically determined low back moments during lifting. Journal of Biomechanics 18: 877-88.

Mirunalini A, Esther D, Deepika J (2015) Characterization of drudgery in cotton production aystems. International journal of Agricultural Science 5 : 147-152. 
Nordgren TM, Bailey KL (2016) Pulmonary Health Effects of Agriculture. Current Opinion in Pulmonary Medicine 22 : 144-149.

Oxman AD, Muir DCF, Shannon HS, Stock SR, Hnidzo E, Langi HJ (1993) Occupational dust exposure and chronic obstructive pulmonary disease. American Review of Respiratory Diseases 148: 38-48.

Paul SP, Mitra K, Chakrabarty A, Das DK (2019) Prevalence of Musculoskeletal Disorders and its Correlates among Agricultural Workers in Bhatar Block of PurbaBardhaman District, West Bengal. IOSR Journal of Dental and Medical Sciences 18 : 22-28.

Pradhan CK., Thakur S, Chowdhury R (2007) Physiological and subjective assessment of food grain handling workers in West Godavari District, India. Industrial Health 45: 165-169.

Pranav PK, Biswas M (2016) Mechanical intervention for reducing dust concentration in traditional rice mills. Industrial Health 54: 1-9.

Puttewar AS, Jaiswas SB (2014) An empirical study of posture related discomforts in rice mill workers, International journal of research in Aeronautical and Mechanical Engineering $2: 50-54$.

Said AM, AbdelFattah EB, Almawardi AM (2017) Effects on respiratory system due to exposure to wheat flour. Egyptian Journal of Chest Diseases and Tuberculosis 66 : 537-548
Schenker MB, Pinkerton KE, Diane Mitchell D, Vallyathan V, Elvine-Kreis B, Green FHY (2009) Pneumoconiosis from Agricultural Dust Exposure among Young California Farmworkers. Environmental Health Perspectives 117 : 988-994.

Sen RN, Nag PK (1975) Work organization of heavy load handling in India. Journal of Human Ergology 4: 103-113.

Swedish National Board of Occupational Safety and Health (1991) Ordinance (AFS 1990: 13) On Occupational Exposure Limit Values, Stockholm, Sweden.

Taskar VS, Coultas DB (2006) Is Idiopathic Pulmonary Fibrosis an Environmental Disease? Proceedings of American Thoracic Society 3: 293-298.

Taytard A, Tessier JF, Vergeret J, Pellet F, Faugere JG, Gachie JP, Beziau F, Kombou L, Fontan J, Redon S, Rio P, Freour $P$ (1998) Respiratory function in flour-mill workers. European Journal of Epidemiology 4 : 104-109.

WHO (1995) Physical status: the use and interpretation of anthropometry. WHO Technical report Series No. 854, WHO, Geneva.

Yach D, Myers J, Bradshaw D, Benatar SR (1985) A respiratory epidemiologic survey of grain mill workers in Cape Town, South Africa. American Review of Respiratory Diseases 131: 505-510. 